\title{
Association between Helicobacter pylori infection and primary open- angle glaucoma
}

\author{
Sayaka Sultana, Nazneen Khan, Chonchol Kumar Ghosh, Ahmed Abu Saleh and Md. Shafiqul Islam
}

\begin{abstract}
Article Info
Department of Ophthalmology, Faculty of Surgery, Bangabandhu Sheikh Mujib Medical University, Shahbag, Dhaka, Bangladesh (SS, NK, MSI); Department of Gastroenterology, Faculty of Medicine, Bangabandhu Sheikh Mujib Medical University, Shahbag, Dhaka, Bangladesh (CKG); Department of Microbiology and Immunology, Faculty of Basic Science and Paraclinical Science, Bangabandhu Sheikh Mujib Medical University, Shahbag, Dhaka, Bangladesh (AAS)

For Correspondence:

Sayaka Sultana

sultanasayaka@gmail.com

Received:

Accepted:

Available Online:

ISSN: 2224-7750 (Online) 2074-2908 (Print)

DOI: 10.3329/bsmmuj.v12i1.40484
\end{abstract}

Cite this article:

Sultana S, Khan N, Islam MS. Association between Helicobacter pylori infection and primary open-angle glaucoma. Bangabandhu Sheikh Mujib Med Univ J. 2019; 12: 25-28.

Copyright:

The copyright of this article is retained by the author(s) [Atribution CC-By 4.0]

Available at:

www.banglajol.info

A Journal of Bangabandhu Sheikh Mujib Medical University, Dhaka, Bangladesh

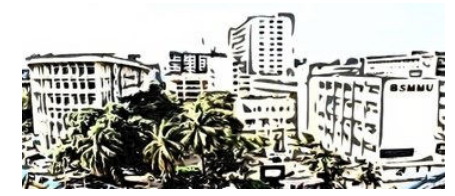

\section{Abstract}

The pathological processes of primary open-angle glaucoma is unknown. Several studies show the relation between Helicobacter pylori infection and primary open-angle glaucoma. The purpose of this study was to assess the association between $H$. pylori infection and primary open-angle glaucoma. Forty patients of diagnosed primary open-angle glaucoma were selected as case and 40 participants without primary open-angle glaucoma were selected as control as per inclusion and exclusion criteria. Complete clinical evaluation including history, physical examination, relevant ocular examinations and laboratory investigations were performed. Serologic evidence of $H$. pylori infection was found in $75 \%$ of patients with primary open-angle glaucoma and $30 \%$ of patients without primary open-angle glaucoma which achieved statistically significant difference $(\mathrm{p}=0.000$, $\mathrm{OR}=7.00$ and $\mathrm{CI} 95 \%=2.61-18.74) .{ }^{13} \mathrm{C}$ urea breath test was positive in $70 \%$ in case group and $37.5 \%$ in control group which also achieved statistically significant difference $(p=0.003, O R=3.89$ and CI $95 \%=1.53-9.87$ ). The findings revealed significant association between $H$. pylori infection and primary open-angle glaucoma.

\section{Introduction}

Primary open-angle glaucoma is the most common cause of irreversible blindness worldwide. 1 It is usually bilateral which is adult onset characterized by an intraocular pressure more than $21 \mathrm{mmHg}$ at some stage, glaucomatous optic nerve damage, an open anterior chamber angle, characteristic visual field loss as damage progresses, absence of signs of secondary glaucoma or a non-glaucomatous cause for the optic neuropathy. The pathologic processes of glaucoma still remains hidden in many points. Agedness, hereditary and raised intraocular pressure may be responsible factors. Changes in endothelin-dependent vascular regulation, cytokine-dependent platelet aggregation which impaired ocular blood flow, influencing apoptotic process and apoptotic loss of optic disk neurons and other autoimmune mechanisms which may induce and/or exacerbate glaucomatous optic neuropathy. $\underline{\underline{2-4}}$

Helicobacter pylori is a Gram negative bacterium which causes many upper gastrointestinal diseases. It mainly resides in the stomach, but it also produces a systemic host immunologic response and the release of various vasoactive and pro-inflammatory substances. Thus, $H$. pylori may be partly responsible for the occurrence of diseases in extradigestive areas such as ischemic heart disease, cardiovascular disease, Raynaud's phenomenon and migraine. Another likely association is the glaucoma which thought to linked with $H$. pylori through some mechanisms include: Stimulating aggregation of platelet and platelet-leucocyte, stimulating release of pro-inflammatory and vasoactive substances, inducing cross mimicry between endothelial and $H$. pylori antigens and promoting apoptotic process. $\frac{5}{\text { Recently various }}$ debate about their association. 6 Some studies in Greece, china, Iran, and Australia have reported relatively higher association between $H$. pylori infection and open-angle glaucoma.7-11 However, other studies in Canada and Iran have not reported statistically significant differences between them. $\frac{12-14}{}$ Other studies found that eradication of $H$. pylori may be beneficial in the management of chronic open-angle glaucoma. 15 Thinking about these dispute, this study was done to compare the association of $H$. pylori infection in patients having primary open-angle glaucoma and control group of participants.

\section{Materials and Methods}

This study was carried out from March, 2015 to August, 2017. Forty patients with primary open -angle glaucoma were selected as case and 40 patients as control group as per inclusion and exclusion criteria. The selection criteria of cases 
were age between $40-80$ years, intraocular pressure $\geq 21 \mathrm{mmHg}$, open anterior chamber angle in gonioscopy, optic nerve head changes as glaucomatous, visual field changes such as generalized depression, paracentral scotoma, nasal step. The patient with history of angle closure glaucoma or other kinds of glaucoma, diabetes mellitus, severe systemic disease and neoplasm, other serious eye diseases (corneal opacity, uveitis, central serous chorioretinopathy), previous gastric surgery or treatment of H. pylori eradication were excluded from the study. Inclusion criteria of the controls were age between 40-80 years, intraocular pressure $<21 \mathrm{mmHg}$, normal perimetry, without any glaucomatous optic nerve changes and normotension. The patient with history of angle closure glaucoma or other kinds of glaucoma, diabetes mellitus, severe systemic disease and neoplasm, serious eye disease (corneal opacity, uveitis, central serous chorioretinopathy), previous gastric surgery or treatment of $H$. pylori eradication were excluded from the control. The purpose and procedures were briefly explained to all participants. Following inclusion and exclusion criteria, samples were collected by purposive sampling.

The complete clinical evaluation including history, physical examination, relevant ocular examinations, fundus examination, some special ocular examinations like - intraocular pressure, visual field analysis, gonioscopy were done.

Serologic assays

Table I

Demographic characteristics, gender, antibody titre and ${ }^{13} \mathrm{C}$-urea breath test positivity

\begin{tabular}{|l|r|r|r|r|r|}
\hline & $\begin{array}{c}\text { Primary open- } \\
\text { angle glaucoma } \\
\left(\mathrm{n}_{1}=40\right)\end{array}$ & $\begin{array}{r}\text { Control } \\
\left(\mathrm{n}_{2}=40\right)\end{array}$ & $\mathrm{p}$ value & Odds & $95 \%$ CI \\
\hline Mean age (range) & $\begin{array}{r}51.4 \pm 10.1 \\
(40-75)\end{array}$ & $\begin{array}{r}51.2 \pm 9.9 \\
(40-70)\end{array}$ & 0.929 & & \\
\hline $\begin{array}{l}\text { Gender (male/ } \\
\text { female) } \\
\text { Antibody titer } \\
\text { positivity }\end{array}$ & $24 / 16$ & $24 / 16$ & 1 & & \\
$\begin{array}{l}{ }^{13} \text { C urea breath } \\
\text { test positivity }\end{array}$ & 28 & 12 & 0.000 & 7.00 & 2.61 to 18.74 \\
\hline
\end{tabular}

Table II

Intraocular pressure of study subjects

\begin{tabular}{|l|c|c|}
\hline & $\begin{array}{c}\text { Right eye } \\
(\mathrm{mm} \text { of Hg) }\end{array}$ & $\begin{array}{c}\text { Left eye } \\
(\mathrm{mm} \text { of Hg) }\end{array}$ \\
\hline Patient with primary open angle glaucoma & $21.8 \pm 1.6$ & $21.8 \pm 1.3$ \\
Patient without primary open angle glaucoma & $11.2 \pm 2.5$ & $11.2 \pm 2.5$ \\
p value & $<0.01$ & $<0.01$ \\
\hline
\end{tabular}

For the determination of serum levels of anti-pylori IGg antibody, blood samples were collected and evaluated by ELISA method (DRG H. pylori IgG kitEIA-3057) (positive if anti H-pylori IgG level >20 U/ $\mathrm{mL})$.

\section{Urea breath test}

After an abstinence of proton pump inhibitor for 14 days and fasting for 2 hours, all patients were subsequently subjected to a ${ }^{13} \mathrm{C}$-urea breath test, performed accordance with the manufacturer's recommendations (HCBT-01, Headway ${ }^{13} \mathrm{C}$-Urea Breath Analyzer, China). Patient went through for procedure: a) Blow up the first collection bag; b) take one ${ }^{13} \mathrm{C}$-urea capsule (75 $\mathrm{mg}$ urea); c) wait for $30 \mathrm{~min}$; d) blow up the second collection bag and e) test two bags of breath samples with the analyzer. The results were obtained on-site and expressed as positive or negative.

\section{Statistical analysis}

All data were analyzed by using statistical package for social sciences (SPSS). Associations between two variables were measured by Chi-square test. A probability ' $\mathrm{p}$ ' value of 0.05 or less was considered as significant. Strength of association was determined by estimating odds ratio (OR) and their 95\% confidence intervals (CI).

\section{Results}

The mean age of the patients of both groups were similar. Positive serology of $H$. pylori infection was found in $75 \%$ of patients with primary open-angle glaucoma and $30 \%$ of patients without primary open-angle glaucoma, which was statistically significant ( $p=0.000, O R=7.00$ and CI 95\% $=2.61-18.74$ ). ${ }^{13} \mathrm{C}$-urea breath test was positive in $70 \%$ in case group and $37.5 \%$ in control group, which was significant $(\mathrm{p}=0.003, \mathrm{OR}=3.89$ and CI $95 \%=1.53$ 9.87).

The mean intraocular pressure in right eye and left eye of the patients primary open-angle glaucoma were $21.8 \pm 1.6$ and $21.8 \pm 1.30 \mathrm{~mm}$ of $\mathrm{Hg}$ respectively whereas in control group, the values were $11.2 \pm 2.5$ and $11.2 \pm 2.5 \mathrm{~mm}$ of $\mathrm{Hg}$ respectively for right eye and left eye (Table II). The $\mathrm{p}$ value was found significant $(<0.01)$.

\section{Discussion}

Comparing serology and urea breath test results reveals significantly higher prevalence of $H$. pylori infection in patients with primary open-angle glaucoma.

In the last few years, many studies had conducted for the relationship between $H$. pylori infection and 
the pathological processes of few ocular disorders, such as central serous chorioretinopathy, $\underline{16,17}$ glaucoma, $\underline{18-22}$ blepharitis, and uveitis. The present study found a significant association between $H$. pylori infection and glaucoma.

In the previous studies, only serological method (ELISA) was used to detect $H$. pylori infection because it's a simple test and good for population studies. But it conveys high false positive rates. $.23,24$ Besides, urea breath test shows higher sensitivity $(91.4 \%)$ and higher specificity $(93.8 \%)$ respectively and accuracy (90-93\%) which was nearer with the values for histological examination in the elderly. $\frac{25}{5}$ Therefore, we preferred the ${ }^{13} \mathrm{C}$-urea breath test and serological method both. Endoscopic biopsy is an invasive method and noninvasive tests are more accessible for screening. 1

Greece done the larger period study of this association, used histologic analysis, rapid urease slide test (CLO test) for biopsy, saliva samples and serologic tests, found more frequency of $H$. pylori in glaucoma patients than anemic control group $(\mathrm{p}<0.001)$. 8 Other study announced that eradication of $H$. pylori effectively upgrade glaucoma parameters $(p<.001$ for intraocular pressure; $p \leq 0.01$ for visual field), giving the idea about their causal relationship. $\underline{15}$ Another article explained the inductive theory of apoptosis with H. pylori infection. 6 Another study gave the idea about their possible genetic relationship, proposed this infection as an environmental risk factor for primary open-angle glaucoma. 6 Another study in china performing ${ }^{13} \mathrm{C}$ urea breath method reported significantly higher prevalence of $H$. pylori in patients with primary open-angle glaucoma $(54.2 \%)$ than in control group $(20.8 \%)(p=0.017$ OR=4.49 CI 95\%=1.26-16.01). .7

Another study in Iran found significant difference in seroprevalence of $H$. pylori infection in patients with primary open-angle glaucoma and control group, 89.1 and $59.5 \%$ respectively $(p=0.008) . \underline{22}$

Tsolaki et al. (2015) explain the supposed association between various forms of dementia, including Alzheimer's disease, primary open-angle glaucoma and H. pylori infection in all possible combinations. $\underline{26}$

Zeng et al. (2015) in their meta-interpretive literature found no significant difference regarding the rates of $\mathrm{H}$. pylori infection and ${ }^{14} \mathrm{C}$-urea breath test positivity were observed between the study and control groups $(p=0.473) . \underline{27}$

Some studies reported diverging results. For instance, in one study seropositivity of $H$. pylori and serum level of cytotoxin associated gene-A product was evaluated in both groups, reported that either $H$. pylori infection or seropositivity for virulent cytotoxin associated gene-A bearing $H$. pylori strains do not have significant association with any type of glaucoma ( $\mathrm{p}=0.88$ for $H$. pylori and $\mathrm{p}=0.67$ for Cag-A).12 Other disagreeing studies about the relation between $H$. pylori infection and primary open-angle glaucoma carried out in Canada and Iran. $\underline{13,11}$ Regarding this conflicting results, we used both methods serological test and urea breath test for more accuracy.

In Bangladesh, the prevalence of $H$. pylori infection is high. More than $90 \%$ apparently healthy adults have antibody to $H$. pylori in the blood. $\underline{28}$

Possible explanation of this association is the autoimmune reaction, stimulating platelet and platelet leucocyte aggregation, releasing vasoactive and pro inflammatory factors, sharing common genetic factors which causes apoptosis, impaired ocular circulation, ultimately induces or aggravate glaucomatous damages. 1

\section{Conclusion}

There is significant association between $H$. pylori infection and primary open-angle glaucoma.

\section{Ethical Issue}

The research protocol was approved by the ethical review committee of BSMMU before starting this study. Informed consent was taken from all participants.

\section{References}

1. Kountouras J, Mylopoulos N, Konstas AG, Zavos C, Chatzopoulos D, Boukla A. Increased levels of Helicobacter Pylori IgG antibodies in aqueous humor of patients with primary open-angle and exfoliation glaucoma. Graefes Arch Clin Exp Ophthalmol. 2003; 241: 884-90.

2. Cartwright MJ, Grajewski AL, Friedberg ML, Anderson DR, Richards DW. Immune-related disease and normal-tension glaucoma: A casecontrol study. Arch Ophthalmol. 1992; 110: 500-02.

3. Romano C, Barrett DA, Li Z, Pestronk A, Wax MB. Anti-rhodopsin antibodies in sera from patients with normal-pressure glaucoma. Invest Ophthalmol Vis Sci. 1995; 36: 1968-75.

4. Tezel G, Edward DP, Wax MB. Serum autoantibodies to optic nerve head glycosaminoglycans in patients with glaucoma. Arch Ophthalmol. 1999; 117: 917-24.

5. Kountouras J, Zavos C, Grigoriadis N, Deretzi G, Katsinelos P, Tzilves D. Helicobacter pylori infection as a risk factor for primary open-angle glaucoma. Clin Exp Ophthalmol. 2008; 36: 196.

6. Kountouras J, Zavos C, Chatzopoulos D. Primary open-angle glaucoma: Pathophysiology and treat- 
ment. Lancet 2004; 364: 1311-12.

7. Hong Y, Zhang Ch, Duan L, Wang W. Relationship between Helicobacter pylori infection and open angle glaucoma in China. Asian J Ophthalmol. 2007; 9: 205-08.

8. Kountouras J, Mylopoulos N, Boura P, Bessas C, Chatzopoulos D, Venizelos J, Zavos C. Relationship between Helicobacter pylori infection and glaucoma. Ophthalmology 2001; 108: 599-604.

9. Abrishami M, Kargozar A, Rashed T, Shoeibi N, Attaranzadeh A. Association of Helicobacter pylori infection with primary open-angle glaucoma. Bina J Ophthalmol. 2007; 12: 289-93.

10. Kountouras J, Zavos C, Grigoriadis N, Deretzi G, Katsinelos P, Tzilves D. Helicobacter pylori infection as an environmental familial clustering risk factor for primary open-angle glaucoma. Clin Exp Ophthalmol. 2008; 36: 296-97.

11. Galloway PH, Warner SJ, Morshed MG, Mikelberg FS. Helicobacter pylori infection and the risk for open -angle glaucoma. Ophthalmology 2003; 110: 922-25.

12. Kurtz S, Regenbogen M, Goldiner I, Horowit N, Moshkowitz M. No association between Helicobacter pylori infection or CagA-bearing strains and glaucoma. J Glaucoma. 2008; 17: 223-26.

13. Abdollahi A, Zarei R, Zare M, Kazemi A. Relationship between Helicobacter pylori infection and primary open-angle glaucoma. Iran J Ophthalmol. 2005; 18: 15-19.

14. Izzotti A, Saccà SC, Bagnis A, Recupero SM. Glaucoma and Helicobacter pylori infection: Correlations and controversies. Br J Ophthalmol. 2009; 93: 142027.

15. Kountouras J, Mylopoulos N, Chatzopoulos D, Zavos C, Boura P, Konstas AG, Venizelos J. Eradication of Helicobacter pylori may be beneficial in the management of chronic open-angle glaucoma. Arch Intern Me. 2002; 162: 1237-44.

16. Saccá SC, Pascotto A, Venturino GM, Prigione G, Mastromarino A, Baldi F, Bilardi C, Savarino V, Brusati C, Rebora A. Prevalence and treatment of Helicobacter pylori in patients with blepharitis. Invest Ophthalmol Vis Sci. 2006; 47: 501-08.

17. Cotticelli L, Borrelli M, D'Alessio AC, Menzione M, Villani A, Piccolo G, Montella F, Iovene MR, Romano M. Central serous chorioretinopathy and Helicobacter pylori. Eur J Ophthalmol. 2006; 16: $274-$ 78.

18. Kountouras J, Mylopoulos N, Boura P, Bessas C,
Chatzopoulos D, Venizelos J, Zavos C. Relationship between Helicobacter pylori infection and glaucoma. Ophthalmology 2001; 108: 599-604.

19. Kountouras J, Mylopoulos N, Chatzopoulos D, Zavos C, Boura P, Konstas AGP, Venizelos J. Eradication of Helicobacter pylori may be beneficial in the management of chronic open-angle glaucoma. Arch Intern Med. 2002; 162: 1237-44.

20. Öztürk F, Kurt E, Inan UU, Ermis SS, Çetinkaya Z, Altindis $M$. Is there a relationship between glaucoma and Helicobacter pylori? Afr J Microbiol Res. 2009; 3: 560-64.

21. Deshpande N, Lalitha P, Krishna das SR, Jethani J, Pillai RM, Robin AL, Karthik. Helicobacter pylori IgG anti-bodies in aqueous humor and serum of subjects with primary open angle and pseudoexfoliation glaucoma in a South Indian population. J Glaucoma. 2008; 17: 605-10.

22. Samarai V, Sharifi N, Nateghi Sh. Association between Helicobacter pylori infection and primary open angle glaucoma. Glob J Health Sci. 2014; 6: 13-17.

23. Newell DG, Hawtin PR, Stacey AR, MacDougall $\mathrm{MH}$, Ruddle AC. Estimation of prevalence of Helicobacter pylori infection in an asymptomatic elderly population comparing $\left[{ }^{14} \mathrm{C}\right]$ urea breath test and serology. J Clin Pathol. 1991; 44: 385-87.

24. Thijs JC, Van Zwet AA, Thijs WJ, Oey HB, Karrenbeld A, Stellaard F, Luijt DS, Meyer BC, Kleibeuker JH. Diagnostic tests for Helicobacter pylori: A prospective evaluation of their accuracy, without selecting a single test as the gold standard. Am J Gastroenterol. 1996; 91: 2125-29.

25. Atli T, Sahin S, Arslan BU, Varli M, Yalcin AE, Aras S. Comparison of the C-14 urea breath test and histopathology in the diagnosis of Helicobacter pylori in the elderly. J Pak Med Assoc. 2012; 62: 1061-65.

26. Tsolaki F, Kountouras J, Topouzis F, Tsolaki M. Helicobacter pylori infection, dementia and primary open-angle glaucoma: Are they connected? BMC Ophthalmol. 2015; 15: 24

27. Zeng J, Liu H, Liu X, Ding C. The relationship between helicobacter pylori infection and open-angle glaucoma: A meta-analysis. Invest Ophthalmol Vis Sci. 2015; 56: 5238-45

28. Ahmad MM ${ }^{1}$, Rahman M, Rumi AK, Islam S, Huq F, Chowdhury MF, Jinnah F, Morshed MG, Hassan MS, Khan AK, Hasan M. Prevalence of Helicobacter pylori in asymptomatic population - a pilot serological study in Bangladesh. J Epidemiol. 1997; 7: 251-54 